Aksaray University
Journal of Science and Engineering
e-ISSN: 2587-1277
http://dergipark.gov.tr/asujse
http://asujse.aksaray.edu.tr

Research Article

\title{
Efficiency Analysis for Triple Band RF Energy Harvesting
}

\author{
Aziz Burak Yalcin*, Filiz Sari \\ Aksaray University, Engineering Faculty, Electrical-Electronic Engineering Department, Aksaray, Turkey

\begin{abstract}
In this paper, a multi-band RF energy harvesting circuit is designed. The output voltage and power of the system built at $900 \mathrm{MHz}, 1800 \mathrm{MHz}$ and $2450 \mathrm{MHz}$ frequencies are revealed. All simulations in this paper are made using the Advance Design System (ADS) 2017 program. The load resistances that give the maximum power for each frequency are determined and the appropriate load is selected for all three frequencies. Then, the multi-stage Dickson Voltage Multiplier (DVM) from two to six stages is designed and the number of stages giving the maximum power for each frequency is determined using the selected load. L type and $\pi$ type impedance matching have been applied to obtain the maximum output power in DVM design, which includes this number of stages and has two Schottky diode models (HSMS-2852). Finally, these three circuits are combined and the output voltage and efficiency of the resulting system are analyzed.
\end{abstract}

Keywords: Multi-band radio frequency, Energy harvesting, Dickson Voltage Multiplier, Impedance matching topology, Schottky diode, low power application.

\section{INTRODUCTION}

In parallel with the great increase in the use of wireless communication devices such as mobile phones and $\mathrm{Wi}-\mathrm{Fi}$, the presence of electromagnetic waves in the environment has increased significantly. The phenomenon of collecting this small amount of energy in the environment which is called energy harvesting and converting it into usable electrical energy has recently

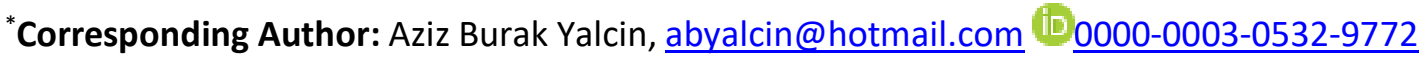


attracted great interest. The biggest factor in this interest is the widespread use of low-power devices and their constant need for energy. This need has led to an increase in the search for alternative methods to obtain low power energy [1,2].

The sun, vibration, heat and electromagnetic waves are important sources of energy. The power density obtained from these sources varies according to the energy source. Solar energy has the highest power density. However, solar energy is used only when the sun is available. Since thermal energy is obtained from the temperature difference in the thermoelectric material, it cannot be used in cases where there is no temperature difference. The energy generated from vibration varies according to the intensity of the applied mechanical vibrations and energy cannot be produced in the absence of vibrations. Compared to thermal or kinetic energy, electromagnetic energy is not limited by field or time. RF wave is present throughout the day both indoors and outdoors, in rural and urban areas. A source designed to detect low power density in the environment can be added and a booster circuit can be created to adapt the requirements of the load application. This makes it convenient to use RF power harvesting for applications such as low-power wireless sensor networks and the Internet of Things (IoT) [3$6]$.

The efficient collection of the energy contained on the electromagnetic waves at radio or microwave frequencies emitting freely in the air with the help of suitable antennas and transferring it to the amplifier and rectifier circuits with high efficiency is called the harvesting of energy from electromagnetic waves [4].

An RF energy harvesting circuit generally consists of parts such as antenna, rectifier, voltage multiplier, impedance matching and energy storage. The antenna used in the RF energy harvesting circuit is an element that converts the electrical field strength in the environment into a voltage difference. The rectifier section rectifies the RF signal coming from the antenna thanks to the diode it contains and regulates it with a capacitor. Thus, it converts the RF signal into a DC (Direct Current) signal. Generally, DC voltage level at the rectifier output of the RF energy harvesting circuit is low. The voltage multiplier part of the harvesting circuit is used to increase this low DC voltage level to a higher DC voltage level. Impedance matching is required for maximum power transfer between all these circuit sections. Impedance matching can be achieved with various techniques in parts where impedance matching is not available. The energy obtained by the RF energy harvesting circuit can finally be stored in the super capacitor or battery or can be directly connected to the device to be fed. Fig. 1 shows the basic components of the RF harvesting system. 


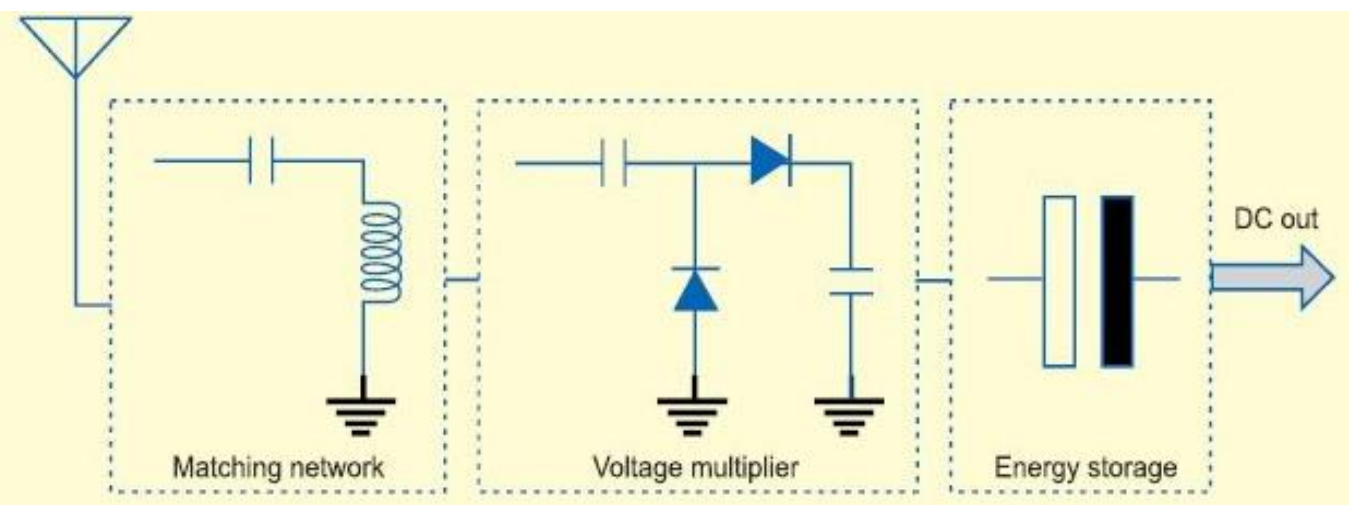

Figure 1. Basic components of the RF harvesting system.

A multi-band RF energy harvesting circuit is designed which is utilized from several single band harvesting system that operates over different frequencies are combined together in [710] to increase the output voltage and efficiency.

In this study, GSM-900, GSM-1800 and Wi-Fi bands are considered for multi-band EH which operates at $900 \mathrm{MHz}, 1800 \mathrm{MHz}$ and $2450 \mathrm{MHz}$ respectively. The load resistances that give the maximum power for each frequency are determined and the appropriate load is selected for all three frequencies. Then, $L$ type and $\pi$ type impedance matching have been applied to the twosix stage Dickson Voltage Multiplier (DVM) and the stage number is determined depend on the maximum efficiency for the respective frequency band. Finally, these three circuits are combined and the output voltage and efficiency of the resulting system are analyzed. All simulations in this paper are made using the Advance Design System (ADS) 2017 program.

\section{VOLTAGE MULTIPLIER}

Voltage multipliers (VM) are used to convert the received AC signal to DC signal and also to amplify the received low level signal. In [11], it is stated that the selection of VM at low input frequencies such as $10 \mathrm{MHz}$ is very important, but this selection is not important for frequencies of $1000 \mathrm{MHz}$ and higher for the un-matched condition, so the DVM shown in Fig. 2 is used for our design.

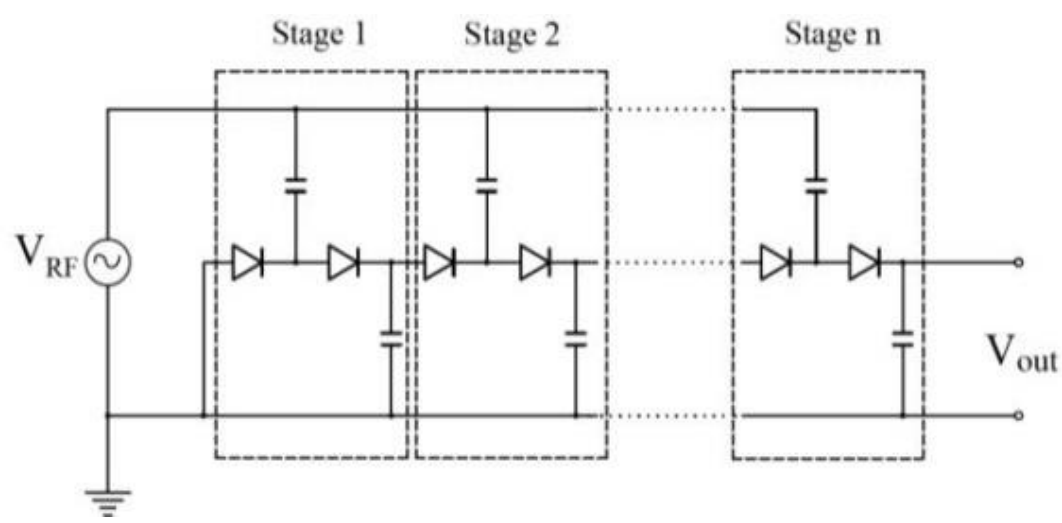

Figure 2. n-stage basic circuit representation of Dickson Voltage Multiplier [5]. 
DVM consists of two diodes and two capacitors and generates DC voltage which is higher than supplied AC signal's maximum voltage [12]. Schottky diodes are chosen for DVM due to its high switching capabilities and low threshold voltage.

\section{IMPEDANCE MATCHING CIRCUITS}

When the source impedance and load impedance are not equal, the received signal will reflect from the load to the source. Therefore, there will be a loss of power in the received signal. The matching circuit ensures that the load impedance is balanced with the source impedance, thus preventing such a power loss. That is, equalizing these impedances prevents signals to be reflected from load to source. The signal is not reflected and the highest power transfer can be made from source to load $[13,14]$ thus efficiency which is defined as the proportion of the output DC power $\left(\mathrm{P}_{\text {out }} \mathrm{t}\right)$ over the input RF power $\left(\mathrm{P}_{\text {in }}\right)$ is increase. The efficiency of this rectifier ( ) could be calculated by using this Equation (1).

$$
\eta=\frac{p_{\text {out }}}{p_{\text {in }}}=\frac{V_{\text {Out }, D C}^{2} / R_{L}}{p_{\text {in }}}
$$

Impedance matching is the second important component of the harvesting system. L type, T type, and $\pi$ type impedance matching networks are some of the impedance matching network topologies as shown in Fig. 3 [15].

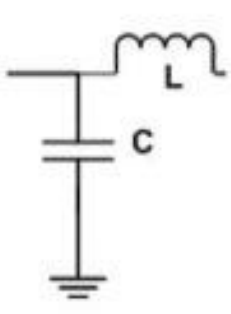

(a)

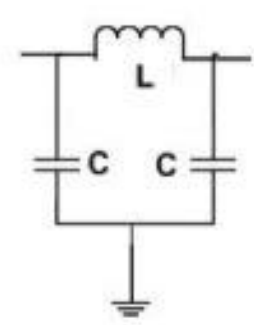

(b)

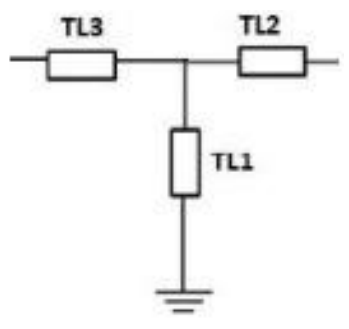

(c)

Figure 3. (a) L type (b) $\pi$ type (c) T type impedance matching networks.

\section{SIMULATION RESULTS}

In order to start the design, first of all the load value must be selected. Input impedance and efficiency of harvesting systems are mainly affected by load resistance. That's why we choose a different load resistance value in our design, from a small resistor $(5 \mathrm{k} \Omega)$ to a large resistor $(100 \mathrm{k} \Omega)$. By looking at the relationship between changing resistance values and output powers, we decide which load resistor to choose to obtain maximum output power. We repeat this on all three frequencies.

Capacitors are set to $100 \mathrm{pF}$ and input power is set to - $15 \mathrm{dBm}$ [10]. HSMS 2852 is chosen for simulation [16] . ADS Harmonic Balance is used in the simulation. When we run the circuit we have created using DVM at $900 \mathrm{MHz}, 1800 \mathrm{MHz}$ and $2450 \mathrm{MHz}$ from 2-stage circuits to 12- 
stage circuits using ADS 2017 at -15 dBm input power, the power values against the load values to determine at what load value is given in Fig. 4.
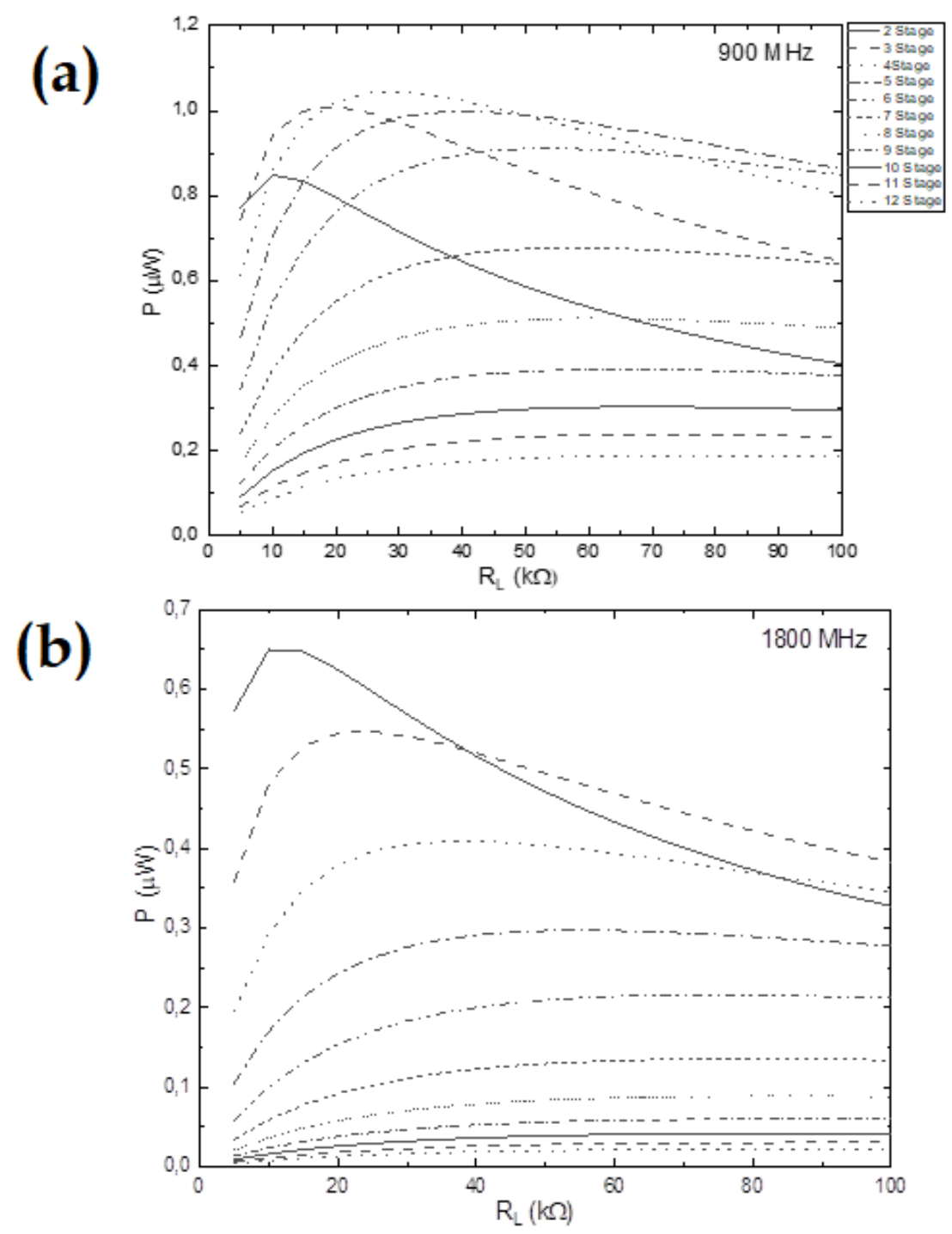

(c)

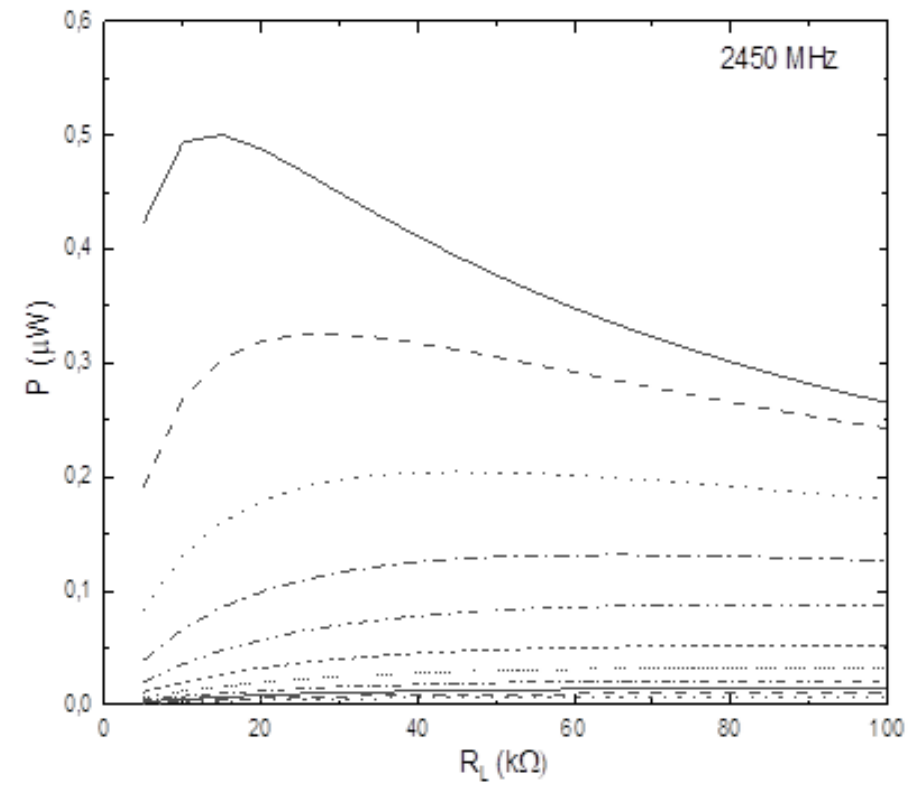

Figure 4. Output power vs load variations depend on the stage number. 
When a common inference is made from the data obtained at 3 different frequencies, it is considered from Fig. 4 that it would be appropriate to choose $20 \mathrm{k} \Omega$ value to be used at every stage of our design in order to obtain the maximum output power, and it is decided to use 20 $\mathrm{k} \Omega$ in the next design stage.

Matching types are applied to two to six stage DVM circuits for $900 \mathrm{MHz}, 1800 \mathrm{MHz}$ and 2450 $\mathrm{MHz}$ to observe which stage gives the highest efficiency. LC, LL and $\pi$ type matching simulation results are given in Fig. 5, Fig. 6 and Fig. 7 respectively.

When the efficiency percentages are analyzed depending on the stage from Fig. 5, maximum efficiency was obtained in 3-stage as $45.382 \%$ for $900 \mathrm{MHz}, 32.882 \%$ in 4-stage at $1800 \mathrm{MHz}$ and $30 \%$ efficiency in 5-stage at $2450 \mathrm{MHz}$.
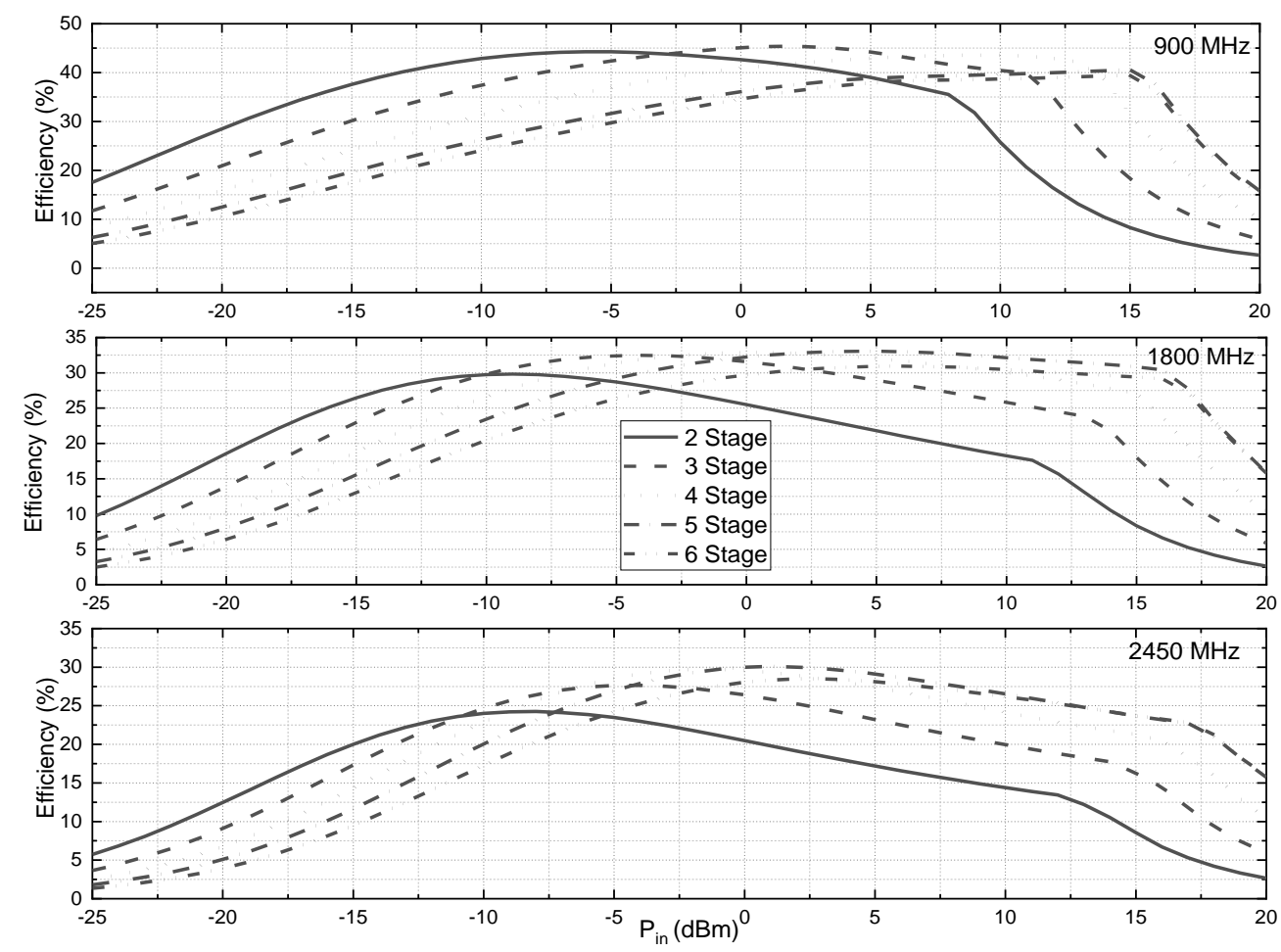

Figure 5. Efficiency vs input power for LC Matching.

For the LL matching efficiency from Fig. 6, maximum efficiency is obtained in 3-stage as $44.792 \%$ for $900 \mathrm{MHz}, 32.975 \%$ in 4-stage at $1800 \mathrm{MHz}$ and $30.144 \%$ in 5-stage at $2450 \mathrm{MHz}$. For the $\pi$ matching efficiency from Fig. 7, maximum efficiency is obtained in 2-stage as $40.426 \%$ for $900 \mathrm{MHz}, 32.384 \%$ in 4-stage at $1800 \mathrm{MHz}$ and $30.638 \%$ in 5-stage at $2450 \mathrm{MHz}$.

From the efficiency analysis, 3-stage circuit at $900 \mathrm{MHz}$, 4-stage circuit at $1800 \mathrm{MHz}$ and 5stage circuit at $2450 \mathrm{MHz}$ are chosen for the combined design of three-band energy harvesting which is given in Fig. 8. 


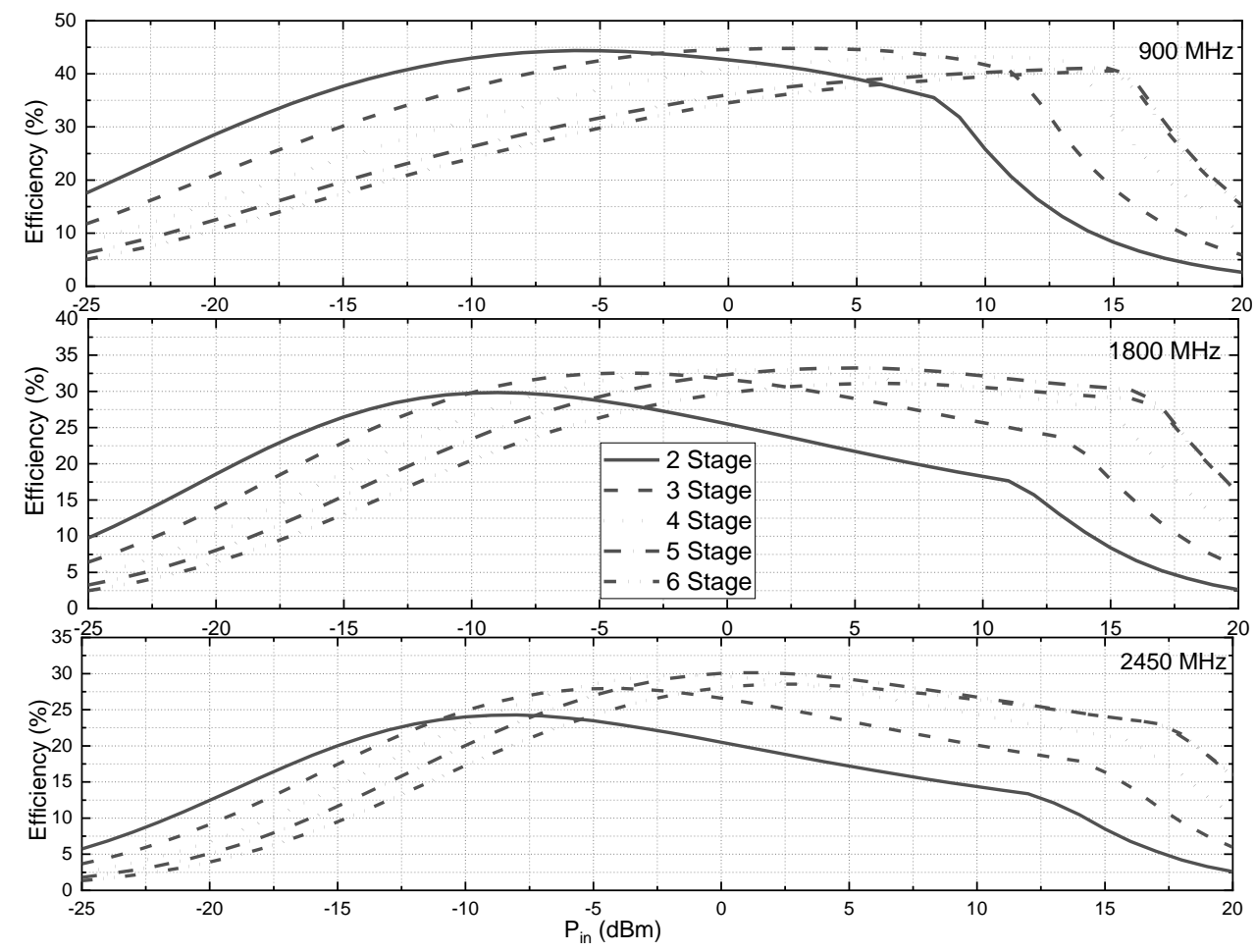

Figure 6. Efficiency vs input power for LL Matching.
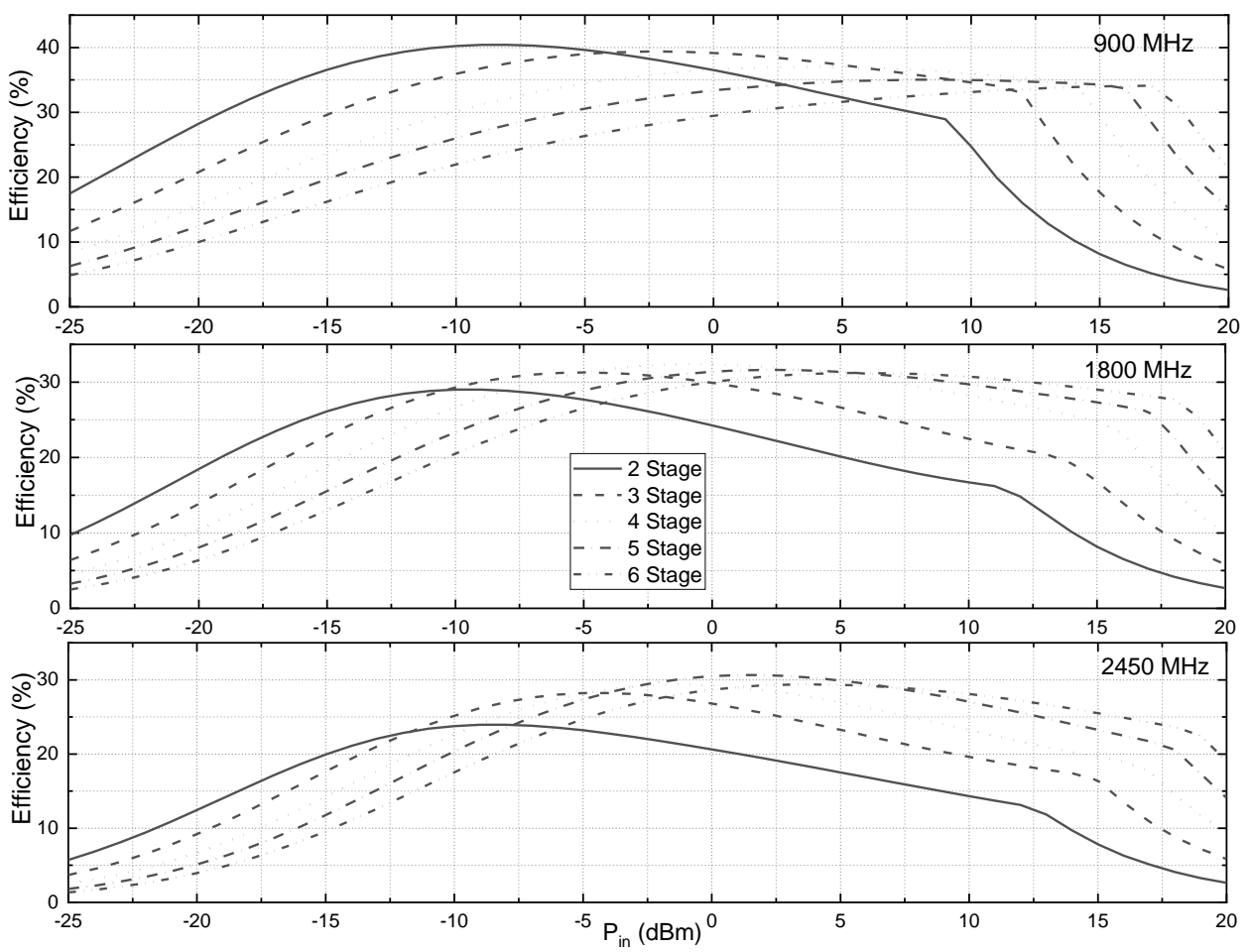

Figure 7. Efficiency vs input power for $\pi$ Matching. 


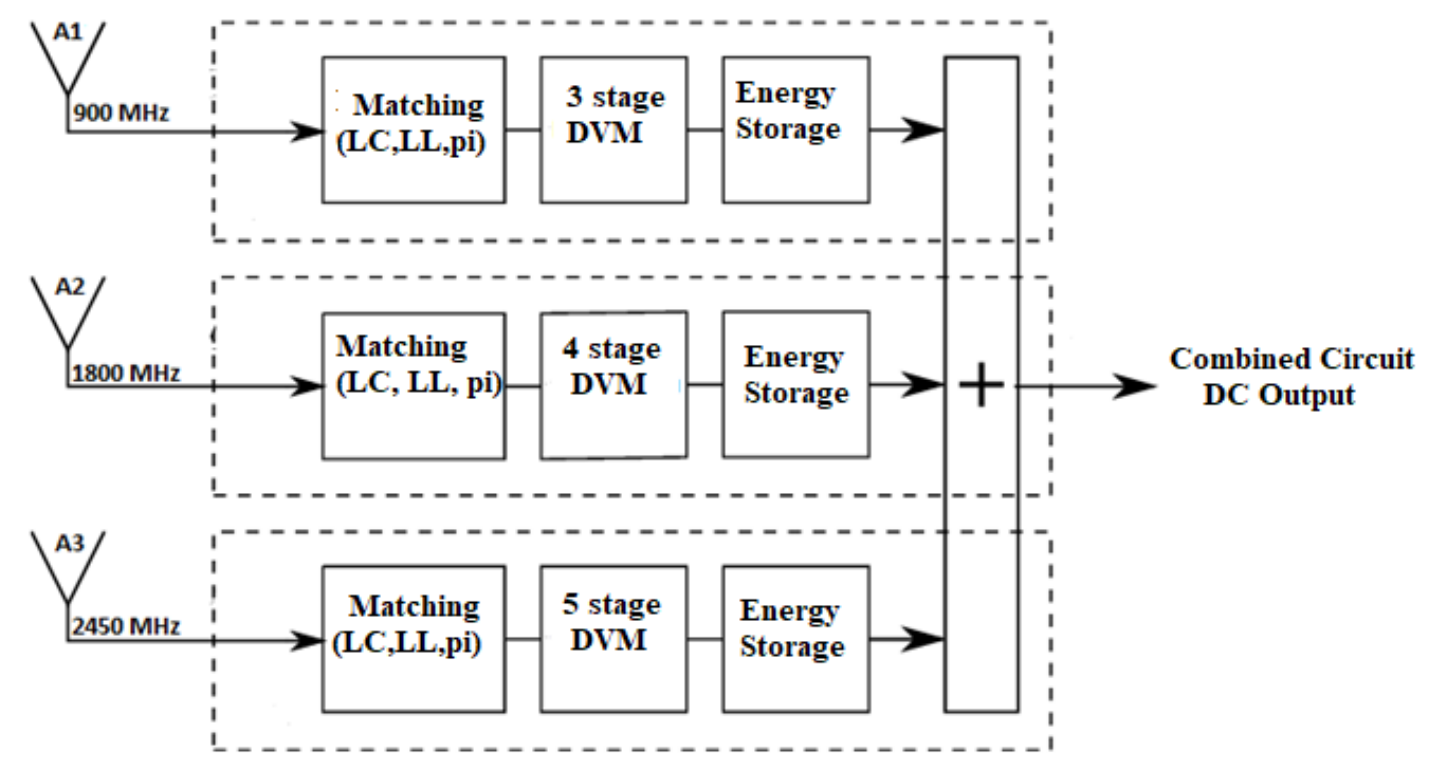

Figure 8. Three-band RF energy harvesting representation.

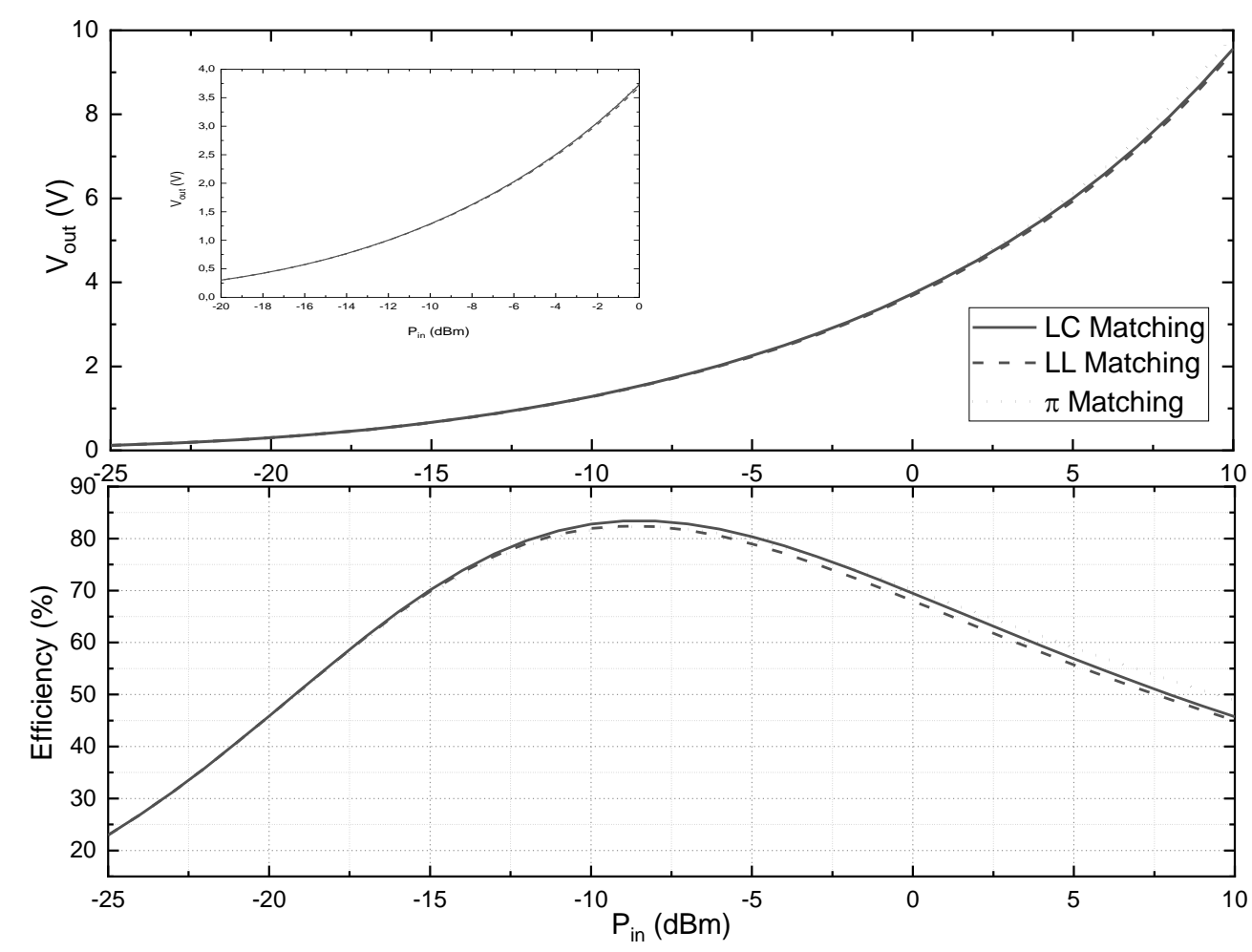

Figure 9. Matching type effect of output voltage and efficiency for combined circuit.

Matching type simulations for combined circuit is given in Fig. 9 depend on the output voltage and efficiency. There are no significant differences observed from the output voltage depend on the matching. Maximum efficiency is obtained for LC matching at $-9 \mathrm{dBm}$ of $83.373 \%$. Thus efficiency of the DVM is increased with triple band. 


\section{CONCLUSION}

In this study, a multi-band RF harvesting system is designed. The voltage multiplier is used not only to rectify the captured radio frequencies, but also to reduce the rectifier impedance to match the $50 \Omega$ antenna. Efficiency and output voltage are the outputs of these designs.

First of all, in determining the load resistance that will give maximum output power for each frequency, the output power of the DVM circuit up to 12-stage are analyzed and it is decided to use $20 \mathrm{k} \Omega$ load resistance. And then, LC, LL and $\pi$ type matching types are applied to DVM circuits for each frequency. Stage numbers for individual frequency are determined depend on the maximum efficiency. 3-stage, 4-stage and 5-stage DVM are chosen for combined triple band circuit. Thus efficiency of the triple band reaches $83.37 \%$ where it reaches approximately $44 \%, 32 \%$ and $30 \%$ efficiency for $900 \mathrm{MHz}, 1800 \mathrm{MHz}$ and $2450 \mathrm{MHz}$ respectively.

\section{REFERENCES}

[1] B.R. Behera, P.R. Meher, S.K. Mishra, Microwave antennas-An intrinsic part of RF energy harvesting systems: A contingent study about its design methodologies and stateof-art technologies in current scenario. Int. J. RF Microw. Computer-Aided Eng. 30 (5) (2020) 1-27.

[2] O. Assogba, A.K. Mbodji, A. Karim Diallo, Efficiency in RF energy harvesting systems: A comprehensive review. IBASE-BF 2020 - 1st IEEE Int. Conf. Nat. Eng. Sci. Sahel. Sustain. Dev. Impact Big Data Appl. Soc. Environ. (2020) 1 - 10.

[3] H.J. Visser, R.J.M. Vullers, RF energy harvesting and transport for wireless sensor network applications: Principles and requirements. Proc. IEEE. 101 (2013) 1410-1423.

[4] F. Akhtar, M.H. Rehmani, Energy replenishment using renewable and traditional energy resources for sustainable wireless sensor networks: A review. Renewable and Sustainable Energy Reviews. 45 (2015) 769-784.

[5] L.G. Tran, H.K. Cha, W.T. Park, RF power harvesting: a review on designing methodologies and applications. Micro and Nano Syst. Lett. 5 (14) (2017).

[6] U. Muncuk, K. Alemdar, J.D. Sarode, K.R. Chowdhury, Multiband ambient RF energy harvesting circuit design for enabling batteryless sensors and IoT. IEEE Internet Things J. 5 (4) (2018) 2700-2714.

[7] Y. Uzun, Design of an efficient triple band RF energy harvester. Appl. Comput. Electromagn. Soc. J. 30 (2015) 1286-1293.

[8] S. Agrawal, M.S. Parihar, P.N. Kondekar, A quad-band antenna for multi-band radio frequency energy harvesting circuit. AEU - Int. J. Electron. Commun. 85 (2018) 99-107. 
[9] H. Tafekirt, J. Pelegri-Sebastia, A. Bouajaj, B.M. Reda, A Sensitive Triple-Band Rectifier for Energy Harvesting Applications. IEEE Access. 8 (2020) 73659-73664.

[10] S. Keyrouz, H.J. Visser, A.G. Tijhuis, Multi-band simultaneous radio frequency energy harvesting. 2013 7th Eur. Conf. Antennas Propagation, EuCAP 2013. (2013) 3058-3061.

[11] F. Sari, Y. Uzun, A Comparative Study: Voltage Multipliers for Rf Energy Harvesting System. Commun.Fac.Sci.Univ.Ank.Series A2-A3. 61 (2019) 12-23.

[12] S. Park, J. Yang, J. Rivas-Davila, A Hybrid Cockcroft-Walton/Dickson Multiplier for High Voltage Generation, IEEE Trans. Power Electron. 35 (2020) 2714-2723.

[13] L. Wu, Design of Radio Frequency Power Amplifiers for Cellular Phones and Base Stations in Modern Mobile Communication Systems. Engineering, Computer Science (2009).

[14] S. Agrawal, S.K. Pandey, J. Singh, M.S. Parihar, Realization of efficient RF energy harvesting circuits employing different matching technique, Fifteenth International Symposium on Quality Electronic Design (2014) 754-761.

[15] R. Rhea, The Yin-Yang of Matching: Part 1-Basic Matching Concepts. High Freq. Electron. 5 (2006) 92-98.

[16] M.M. Al-Azawy, F. Sari, Analysis of Dickson Voltage Multiplier for RF Energy Harvesting, Proc. - 2019 IEEE 1st Glob. Power, Energy Commun. Conf. GPECOM 2019. (2019) 10-14. 